\title{
MÁS ALLÁ DEL ESTADO DE VIDA DE LAS LENGUAS... ELEMENTOS PARA EL DIAGNÓSTICO SOCIOLINGÜÍSTICO DE LA DINÁMICA INTERACTIVA DEL CONTACTO MAPUZUGUN/CASTELLANO
}

Beyond the state of life of languages... Elements for the sociolinguistic diagnosis of the interactive-linguistic dynamic of Mapuzugun/Spanish contact

Aldo Olate Vinet*

Resumen

En este artículo se presentan diversas nociones útiles para explicar las relaciones de complementariedad y antagonismo que ocurren entre lenguas que comparten un espacio geosociocultural determinado. Dicha relación dinámica es reconocida con el nombre de interacción lingüística o interactividad lingüística. Se reflexiona acerca de los procesos dinámicos generados entre el mapuzugun y el castellano y se discuten las descripciones sociolingüísticas realizadas en torno a la lengua mapuche. Se observa que en ellas hay un énfasis en los estados de las lenguas, en las relaciones asimétricas existentes y en los productos finales de esas relaciones, lo que se entiende como una visión generalizada de la situación. Ante esta generalización, se propone la revisión in situ de la interacción lingüística entre el castellano y el mapuzugun y la generación de diagnósticos territoriales que den cuenta de los procesos interactivos, dinámicos, históricos, dialécticos e identitarios, que tienen el mapuzugun y el castellano en las comunidades.

Palabras clave: interacción lingüística, estado de la lengua, contacto lingüístico, bilingüismo.

\section{Abstract}

In this paper we discuss some useful concepts to explain the opposing and complementary relationship between languages that share a specific geosociocultural context. This dynamic relationship is known as linguistic and social interactions. This paper discuss the dynamic processes arising between the mapuzugun and Spanish language, and it also explores some sociolinguistic descriptions about the Mapuche language which are mostly narrow and focus on the asymmetric relationship between languages and the results of these relationships. In this context we propose a new in situ revision of the linguistic interaction to generate territorial diagnostics that consider interactive processes, dynamic and historical, dialectical and identitary concerns that both Spanish and Mapuzugun have in the communities.

Key words: linguistic and social interactions, languages states, language contact, bilingualism.

\section{INTRODUCCIÓN}

En los últimos 25 años los estudios sociolingüísticos concernientes al mapuzugun han presentado afirmaciones categóricas respecto del estado de la lengua, su mantención y desplazamiento, todo lo anterior sustentado en hipótesis del cambio y desaparición. Gundermann et al. $(2009,2011)$, en el marco del análisis de la situación 
actual de la lengua mapuche, retoman la hipótesis de la vitalidad del idioma y señalan que "la dinámica de la lengua mapuche es la de una transformación tendiente a su desaparición y completo reemplazo por el castellano" (Gundermann et al., 2009, p. 51). Se conocen otras dos hipótesis que van en la misma dirección. Se trata de los trabajos de Zúñiga (2007) y de Salas (2006 [1992]), el primero sostiene, a partir de un análisis que integra diversos factores, que el desplazamiento de la lengua es un hecho inapelable. Salas, en tanto, conjetura que la lengua sobrevive en los espacios intracomunitarios. Las descripciones propuestas en estos trabajos construyen una visión general del estado sociolingüístico de la lengua indígena en el territorio nacional.

Por otro lado, existen visiones más reflexivas, que observan cualitativamente los procesos de adquisición y transmisión del mapuzugun y la construcción de la identidad en contextos urbanos. Estos estudios favorecen las historias personales de los hablantes (trayectorias sociolingüísticas) por sobre los censos poblacionales (Wittig, 2009; 2011; Lagos, 2012; 2013).

Desde otra perspectiva, Teiller (2013) discute los datos cuantitativos arrojados por los trabajos de Gundermann et al. (2008) y Zúñiga (2007). Este autor propone una reinterpretación de los datos cuantitativos en el marco de una epistemología basada en el "hablante" y de la "verdadera sociología del lenguaje". Esta idea puede representar un avance reflexivo, pero se observa una idealización de la noción de hablante, el autor no explicita claramente a qué se refiere cuando usa este concepto. Desde una mirada atómica, basada en la competencia lingüístico-comunicativa, el hablante de Teiller parece ser un "monolingüe"; sin embargo, en la situación de contacto, estamos ante un hablante bilingüe. Por otro lado, la noción de "epistemología del hablante" parece dejar de lado las complejidades sociológicas, ideológicas, axiológicas, epistemológicas, antropológicas e históricas contenidas en los hablantes para dar paso a un esencialismo anacrónico.

Otro punto de vista, al que adherimos, se centra en las relaciones establecidas entre el castellano y el mapuzugun dentro de las comunidades ${ }^{1}$. Aquí se atiende al uso, la incorporación del castellano, la alternancia de las lenguas y las variedades utilizadas en los espacios socioculturales (Olate y Bernales, 2014; Olate et al., 2013; Godenzzi, 2007 y 2003; Durán y Ramos 1986, 1987, 1988 y 1989). A diferencia de los planteamientos anteriores, que avalan el desplazamiento, la construcción de la identidad y la perspectiva del "hablante", esta postura se enfoca en el análisis y la descripción de la relación interactiva dada entre el mapuzugun y el castellano en comunidades de habla adscritas a territorios determinados, hecho que activa y hace relevante las historias territoriales.

Si bien son trascedentes los procesos de desplazamiento, de construcción identitaria y la epistemología de los hablantes, no es menos trascedente la relación establecida por las lenguas en las comunidades y territorios, pues al explicitar estas

\footnotetext{
${ }^{1}$ Esta visión está notablemente motivada por las reflexiones presentadas en los estudios de Bengoa $(2007,2014)$ y Zavala (2008).
} 
dinámicas de interacción lingüística se puede: (a) formular una tipología de situaciones bilingües contextualizadas; (b) diagnosticar la mantención o desplazamiento de las lenguas en los territorios; (c) consignar la emergencia de variedades de contacto (mapuzugun de contacto y castellano de contacto) y (d) reconstruir las historias sociolingüísticas de las comunidades con el propósito de conocer las dimensiones culturales, sociales, políticas y económicas que condicionan tanto los dominios sociales de las lenguas como los lingüísticos.

En este artículo profundizamos la posición sociolingüística interactiva mediante la presentación y discusión de conceptos y unidades de análisis fundamentales. Nuestra visión considera la revisión de la dinámica sociolingüística interna de cada comunidad, donde toma sentido la relación histórica establecida entre el mapuzugun y el castellano (Antimil, 2016). Se complementa la discusión con aspectos vinculados al contacto histórico y la configuración y actualización de las lenguas en los territorios.

En este contexto, sostenemos que el problema de la mantención y desplazamiento del mapuzugun se debe observar en función de (1) la interacción lingüística de los hablantes en los ámbitos de uso dados en su comunidad y en los espacios de interacción social que transitan, (2) el posicionamiento político-lingüístico de las comunidades y de los actores (de zonas rurales y urbanas) y (3) hechos históricos y trayectorias sociolingüísticas iniciados hace mucho tiempo y que contienen procesos complejos de interacción, adaptación, de transmisión de ideologías y formación de actitudes.

\section{EL ESTADO SOCIOLINGÜÍSTICO DE UNA LENGUA VS. LOS PROCESOS SOCIOLINGÜÍSTICOS QUE VIVEN LAS LENGUAS}

\subsection{EL ESTADO SOCIOLINGÜÍSTICO DEL IDIOMA MAPUCHE}

Los estudios sociolingüísticos acerca del mapuzugun han tenido un desarrollo discontinuo en los últimos 40 años. En Chile, durante la década de 1980, encontramos los trabajos pioneros de Croese (1983) y Durán y Ramos (1986, 1987, 1988, 1989), estudios que abordan, desde ópticas distintas, la condición sociolingüística del mapuzugun. Para Croese (1983), el mapuzugun tiene gran vitalidad y coexiste con el sistema de parentesco y con la participación activa en los ritos religiosos, lo que permite mirar con optimismo la persistencia de la cultura mapuche.

Desde un enfoque más antropológico, Durán y Ramos describen la relación entre el mapuzugun y el castellano y cómo este último fue incorporado por la población mapuche. Esta mirada la detallaremos en el siguiente apartado.

En la década de 1990 encontramos el trabajo de Salas (2006), el que no es precisamente sociolingüístico sino lingüístico descriptivo. Existe, sin embargo, un cúmulo de ideas sostenidas por este autor en las que indirectamente propone sus 
hipótesis acerca del estado de la lengua, inclinándose por la idea del uso restringido de la lengua en espacios intraétnicos.

La década del 2000 se inaugura con diversos trabajos, entre ellos encontramos los de Gundermann (2005), Zúñiga (2007), Gianelli (2007), Gundermann et al. (2008, 2009, 2011), en ellos se observa una tendencia general que busca mostrar el estado del mapuzugun, lo que nos lleva al problema del desplazamiento progresivo de la lengua y su remplazo por el castellano.

Se observa que en estos 40 años de investigación sociolingüística hay una tendencia que, al parecer, proyecta una situación de cambio y sustitución del mapuzugun por el castellano. Aquí, las etiquetas son diversas, desplazamiento en curso (Gundermann, 2009), desplazamiento inapelable (Zúñiga, 2007), lengua minoritariamente enseñada en casa (Gianelli, 2007), entre otras. Todo lo anterior redunda en la penetración del castellano en los espacios comunicativos mapuches, lo que se traduce en el uso del español como la lengua de comunicación comunitaria. La crítica hacia estos trabajos está en la falta de problematización relacionada con los marcos y procesos históricos de interacción y contacto que implican la incorporación del castellano.

\subsection{LA INTERACCIÓN SOCIOLINGÜÍSTICA DE LOS IDIOMAS, LA EMERGENCIA DEL BILINGÜE Y EL PROCESO HISTÓRICO DE DESARROLLO}

Los trabajos de Durán y Ramos (1986, 1987, 1988 y 1989) proponen una mirada de proceso, no de estado, lo que implica una percepción dinámica, de interacción, dada entre las lenguas en contacto, la que se condiciona por un marco histórico, geográfico y sociopolítico de desarrollo. El énfasis está tanto en la incorporación del castellano por los mapuches como en la relación que establece el mapuzugun con la lengua extranjera. En esta perspectiva, el estado sociolingüístico de una lengua es menos relevante que el proceso por el que la lengua foránea, producto de procesos sociopolíticos y presiones sociocomunicativas, ha sido incorporada por el pueblo mapuche.

La cuestión básica planteada por Durán y Ramos (1986) es “cómo los mapuches en tanto individuos y en tanto miembros de un grupo étnicamente diferenciado, han incorporado la lengua extranjera, perteneciente al grupo que los conquistó, colonizó y permanece como aquel que determina su vida social" (p. 18). La interrogante explicitada implica la comprensión del contacto de occidentales y mapuches, entendiendo la relación en un sentido bidireccional, esto es, en palabras de Durán y Ramos (1986), "cómo los occidentales conciben el contacto con los aborígenes" y "cómo los mapuches han enfrentado y definen su propia identidad étnica y social a partir del contacto desencadenado por los occidentales" (p. 18). Dados estos supuestos, se postula una gradiente de rechazo/aceptación del español por parte de los mapuches, este continuo debe interpretarse desde un marco histórico, en un extremo hay un estado inicial de rechazo del castellano, mientras que en el otro hay un estado de incorporación 
masiva del español en las comunidades y en la vida de los hablantes. Lo que en un inicio fue la adopción obligada/forzada de la lengua -estado de rechazo-, hoy es adopción voluntaria -incorporación masiva-(Durán y Ramos, 1986).

En este contexto, el problema acerca del estado sociolingüístico del mapuzugun, su vitalidad, vigencia y mantención, ha ignorado el marco histórico que ha vivido la lengua mapuche en su proceso de contacto extendido. Esta relación sociohistórica compleja tiene repercusiones evidentes en los sistemas de comportamiento sociales y lingüísticos. Los hablantes de la lengua minorizada viven los conflictos en la historia de conquista y colonización, espacio donde se forjan escenarios cambiantes que implican nuevos agenciamientos. Por esto, el hablante y la situación bilingüe deben entenderse en función de trayectorias sociolingüísticas condicionadas por la política, la economía, la demografia y los procesos socioculturales del escenario histórico.Desde una perspectiva sociolingüística, si asumimos los procesos de colonización, conquista y occidentalización experimentados por el pueblo mapuche, entonces, "los contactos sociopolíticos, inspirados por afán de dominio y conquista, traen como consecuencia el contacto cultural obligado de los pueblos, del que la adquisición y aprendizaje de una lengua distinta son un aspecto más" (Durán y Ramos, 1986, p. 20).

En este marco interactivo, que posiciona el contacto como un hecho presente, se infiere que una dimensión a tener en cuenta en la activación de la adquisición de una lengua es la sociopolítica, esta condiciona los procesos adquisitivos futuros. Por lo tanto, la respuesta al problema del desplazamiento de la lengua mapuche es evidente, los factores históricos, políticos y sociocomunicativos que implican el proceso de incorporación del castellano por parte del pueblo mapuche están en la base.

Otra dimensión, que va de la mano con las visiones sociolingüísticas estáticas, es el problema de la valoración social de la lengua que está en proceso de desplazamiento. En nuestro caso, el mapuzugun es una lengua estigmatizada, no es una lengua de "alta cultura" (Salas, 1983), llegando a extremos de catalogarlo como dialecto. Pues bien, si asumimos las premisas de Durán y Ramos $(1986,1987)$, entonces debemos preocuparnos por los procesos en que una lengua se torna valiosa para la sociedad que la habla, el resultado de esta reflexión nos lleva a la idea de que la valoración de la lengua es social. La aceptación de lo anterior nos invita a presuponer que la valoración del mapuzugun se condiciona a los hechos históricos por los que han transitado sus hablantes.

Toma sentido entonces la explicación comúnmente dada respecto de las razones por las que se deja de hablar mapuzugun, o por las que no se enseña en las comunidades, pues hay varias generaciones de mapuches que vivieron procesos de estigmatización social y castigo por la práctica de su lengua (Comunidad de Historiadores Mapuche, 2014; Antimil, 2016; Antimil y Olate, en arbitraje). Si a ello sumamos la relevancia sociopolítica y comunicativo-funcional que ha tenido el castellano desde la Ocupación de la Araucanía hasta nuestros días, entonces se infiere 
que la valoración de la lengua mapuche será menor que la del castellano (Lagos y Espinoza, 2013).

En la mirada interactiva hay tipos de contacto que se relacionan con los espacios e instituciones socioculturales en que los hablantes usan las lenguas. Así, si se entiende el contacto como la configuración y actualización de las lenguas en los territorios, y su desarrollo en los hablantes, este se puede observar a partir de los hitos sociohistóricos que cruzan las trayectorias lingüístico-sociales de los hablantes, provocando procesos de interacción y adaptación en escenarios de colonización. La historia del territorio contiene la historia de las lenguas en contacto, allí se aprecian los contextos de interacción originarios que establecen las relaciones de poder y subordinación de los códigos.

\subsection{BREVE HISTORIA INTERACTIVA ENTRE EL MAPUZUGUNY EL CASTELLANO}

La relación entre las lenguas no es homogénea, por el contrario, es heterogénea y pluridireccional, se fundamenta tanto en los tipos de relaciones históricas y sociopolíticas establecidas entre colonizadores y colonizados como en las estrategias y necesidades comunicativas que los hablantes deben desarrollar en estos contextos (Olate, 2017).

Desde una perspectiva basada en la relación social de las dos lenguas, el contacto entre el mapuzugun y el castellano puede abordarse a partir de: (1) la instalación de contextos de uso lingüísticos occidentales en espacios no occidentales y (2) la incorporación del castellano y el surgimiento de la condición bilingüe con fines pragmáticos, funcionales y de supervivencia (Bengoa, 2007, 2014; Olate, 2017).

El continuo histórico del contacto mapuche/castellano presenta dos momentos, el primero con conquistadores españoles y su imperio, y el segundo con los conquistadores criollos y su proyecto nacional.

En cuanto al primer momento, la sociedad mapuche tuvo que adecuarse a los nuevos contextos traídos por la empresa colonialista hispánica, la que implantó grupos militares, religiosos y comerciantes, escenario que redundó en la emergencia de ámbitos de uso (espacios civilizatorios) adscritos a lógicas culturales inexistentes. La tarea, por tanto, fue la de adaptarse a estos nuevos contextos y adquirir las herramientas comunicativas para enfrentarlos (Bengoa, 2007, 2014).

Durante la primera conquista proliferaron los ámbitos de intercambio lingüístico, Durán y Ramos (1986) señalan que los espacios de interacción emergidos fueron la guerra, los intérpretes, el cautiverio, la educación y el comercio. Estos nuevos contextos modificaron los comportamientos socioculturales de la sociedad mapuche, provocando una acomodación a la situación y procesos de comprensión intercultural desde el conquistado hacia el conquistador (Bengoa, 2007). Las mismas autoras afirman que el proceso sociolingüístico e interactivo de la primera conquista se extendió al siglo XVII, lo que se tradujo en fijación de ámbitos y la implementación de nuevos dominios de uso. 
Durante este período de conquista, debido a la resistencia mapuche y su rápida adaptación, se configuró una relación de convivencia entre el mapuzugun y el castellano. Los intercambios se dan en las instituciones culturales introducidas por medio de ámbitos de uso, instancias donde se activan procesos de aprendizaje intercultural que permiten la comprensión, por parte de la sociedad mapuche, del primer escenario de conquista. Por ello se resuelve la incorporación funcional y pragmática del castellano por parte de los cacicazgos mapuches (Bengoa, 2007). La frontera y el territorio Mapuche se constituyeron, durante este período, en un polo de comercialización, cuyo movimiento fluctuaba en tres esferas: comercio intraterritorial, comercio regional y comercio extrarregional. La idea de alcanzar la estabilidad económica contribuyó a fortalecer las relaciones fronterizas y a consolidar la cohabitación entre mapuches, conquistadores y criollos (Pinto, 2000).

Por otro lado, respecto de la difusión del castellano en el territorio (o la ampliación geosocial de la lengua), se observa que no todos los hablantes del territorio mapuche tuvieron acceso a la misma intensidad de interacción con el conquistador español. Se infiere, por tanto, que el castellano no se extendió tan profundamente en La Araucanía. El bilingüismo, el epu kimün, se instaló como necesidad para negociar e intercambiar en la frontera. Por ello, los cacicazgos mapuches procuraban que sus descendientes adquirieran la lengua del conquistador (Zavala, 2008; Bengoa, 2007).

En resumen, ante la pregunta de la incorporación funcional y pragmática del castellano por parte de la sociedad mapuche durante este periodo, diremos que el castellano fue incorporado en los ámbitos que instaló el conquistador, en estos espacios, los hablantes se vieron obligados a utilizar el código foráneo como herramienta comunicativa. Sin embargo, este proceso no impactó de forma homogénea en todo el territorio (Olate, 2017).

El segundo momento implica el ingreso de instituciones occidentales, entendidas como espacios civilizatorios (Nahuelpan, 2012, 2013), al territorio mapuche y al inicio de procesos asimilatorios intensos respecto de la sociedad (Bengoa, 2014). Durante esta época, la situación sociopolítica y de contacto lingüístico cambió radicalmente, generando la subordinación de la lengua mapuche. La relación previa se transforma en una situación de subordinación, desprestigio e imposición (Bengoa, 2000). Esta etapa se caracteriza por el ingreso de los colonos, las misiones, el despojo de tierras, la instalación del Estado de Chile y sus instituciones castellanizantes en La Araucanía (Lagos y Espinoza, 2013; Olate, 2017).

Un aspecto fundamental de este segundo período fue la castellanización formal mediante la escuela y la obligatoria burocracia en castellano. Durán y Ramos (1988) enfatizan que la escolarización fue uno de los recursos que tuvo mayor impacto en los procesos asimilatorios, pues se articuló desde la idea de una formación integral, anclada en la doctrina cristiana, fomentando el uso del castellano como lengua oficial. 
Otros espacios que se activan postocupación de La Araucanía son: ámbitos administrativos (por creación de provincias), extensión de las redes de comunicación, transformación de los fuertes en pueblos y ciudades con actividad comercial. El proceso que se produce en el territorio mapuche emana de las acciones que el Estado promovió con el claro objetivo de instalarse en el territorio e imponer el castellano como lengua oficial (Durán y Ramos, 1988).

La promoción de estos espacios civilizatorios genera un contacto intenso entre el castellano y el mapuzugun, posicionando al primero como lengua dominante, y al segundo como dominada.

La importancia de los ámbitos de uso y de la historia del contacto entre el mapuzugun y el castellano puede seguirse a partir de las siguientes dos reflexiones.

(1) Si se asume una perspectiva que considera la formación de un sujeto bilingüe en su dimensión social, debe consignarse que las relaciones sociales y los ámbitos de uso son instancias activadoras del bilingüismo en los individuos (Silva Corvalán, 2001). Por ello, el establecimiento e introducción de instituciones ajenas a la sociedad mapuche tradicional opera como precursor del bilingüismo funcional del castellano entre los miembros del territorio. En estas situaciones, la competencia del hablante se verá condicionada por las presiones comunicativas implícitas de los espacios de interacción social y de los dominios de uso de las lenguas introducidas por el colonizador.

(2) En cuanto al proceso histórico, se observa, por un lado, un proceso global que da cuenta de las etapas -generales- en que se da la interacción entre conquistadores y conquistados, pero además, puede fijarse una mirada específica que da cuenta del ingreso del castellano o su instalación en los territorios particulares. Este no fue homogéneo, por el contrario, fue gradual y lo es hasta nuestros días. La incorporación del castellano y la emergencia de comunidades bilingües se dan en la heterogeneidad y se aferra a las situaciones histórico-territoriales e identitarias particulares que perviven en comunidades a partir de la Ocupación de La Araucanía.

\section{ALGUNAS HERRAMIENTAS CONCEPTUALES PARA DIAGNOSTICAR LA INTERACCIÓN LINGÜISTICA EN LAS COMUNIDADES}

Al estudiar la interactividad lingüística de las lenguas, no debe preconcebirse el estado de una lengua sobre la otra. Lo ideal es observar las dinámicas dadas entre estas, con el objeto de construir una mirada que dé cuenta de ambos polos de la relación, es decir, desde el mapuzugun al castellano y viceversa. La clave para lograr el retrato de este continuo de usos, transmisiones y actitudes está en la adopción de diversos planteamientos que mostraremos a continuación. 
Más allá del estado de vida de las lenguas...

\subsection{LAS CONDICIONES DE INTERACCIÓN}

Según nuestro punto de vista, las descripciones sociolingüísticas han operado desde posiciones que privilegian el estado de una lengua por sobre procesos sociolingüísticos dinámicos, históricos, dialécticos e interactivos dados en las comunidades. La idea de generalizar un "estado" de la lengua no es negativa en sí, pues por ella se logra constituir una mirada de la situación, pero se pierde el dato particular que da cuenta de la razón por la que ese "estado" propuesto es tal en las diversas comunidades.

Las comunidades perfilan sus comportamientos lingüísticos y sociolingüísticos hacia el mapuzugun o el castellano sobre la base de las condiciones de interacción históricas generadas en estos espacios. Una condición de interacción puede entenderse como un escenario comunicativo regido por algún factor extralingüístico (político, administrativo, cultural, económico, religioso, judicial) que compromete la voluntad lingüística del hablante y promueve, en la esfera de uso de las lenguas, un "comportamiento congruente" con las funciones sociales y comunicativas en la que se ve envuelto, cuestión que repercute en la transmisión y las actitudes (lealtad, prestigio, invisibilización, estigmatización) lingüísticas y sociolingüísticas.

A modo de ejemplo, supóngase una comunidad/reducción, cuyos miembros provienen de distintos territorios, articulada a partir de la Ocupación de la Araucanía y que tiene a su alrededor varios fundos. Obviamente, en torno al fundo se generará mucha interacción en la lengua dominante, por lo que los integrantes de la comunidad/reducción se verán en la obligación de incorporar la lengua del dueño del fundo para poder interactuar. El estado actual de la lengua en esa comunidad no podemos describirlo por medio de una foto tomada en un momento. La imagen tiene ese actual estado por el proceso sociohistórico, por las condiciones de interacción, por lo que será necesario describir el momento presente en atención a la progresión histórica observada entre los códigos en contacto.

En este ámbito, el sentido de la afirmación: "la lengua mapuche está en proceso de desplazamiento", tiene que ver con la evolución histórica de las condiciones de interacción entre ambas lenguas, en el entendido de que en estas condiciones hay factores extralingüísticos subyacentes, los que restringen, monopolizan e ideologizan las decisiones lingüísticas de los hablantes minorizados. La afirmación debería movernos a capturar la historia sociolingüística (McColl, 2012) de las comunidades y lenguas y a proyectar, en este caso, la emergencia de las situaciones de bilingüismo social.

\subsection{AlgunAS CATEGORÍAS DE ANÁLISIS RELEVANTES}

La clave está en generar dos miradas sobre un mismo territorio. Una mirada histórica que busque la comprensión de la configuración territorial de la comunidad y otra mirada sociolingüística que permita establecer la relación de uso y transmisión de las lenguas. Desde el dominio sociolingüístico, las categorías que se deben investigar son: eventos comunicativos (ámbitos de uso), transmisión generacional, temas, 
géneros y discursos y, finalmente, percepciones. Desde una mirada histórica, debe explorarse la historia de la comunidad, cómo se formó, la organización económica del territorio, los procesos de escolarización y su estructura sociopolítica.

\section{a. Ámbito de uso/dominio}

Un ámbito de uso se relaciona con los contextos institucionales y culturales que hay en la comunidad. Estos designan y clasifican las situaciones de interacción y la frecuencia con la que ocurren. De este modo, los ámbitos de uso son útiles para conocer la preferencia de los hablantes hacia el uso de una lengua u otra en el marco de los sucesos culturales adscritos a su comunidad (Fishman, 1974, 1982; Romaine 1996; Olate y Bernales, 2014; Olate et al., 2013). La designación de un ámbito implica el conocimiento de la dinámica sociocultural de los ambientes estudiados en determinados momentos históricos de la comunidad.

La noción de dominio, al igual que los ámbitos, se entiende como puntos de anclaje de los sistemas de valores vinculados al uso de una lengua por contraste con otra. El dominio es una abstracción que se refiere a esferas de actividades donde se combinan tiempos, lugares y papeles sociales específicos (Romaine 1996). Son determinados por los temas de discusión, por las relaciones de roles y por el espacio físico o lugar donde ocurre la interacción (Saville Troike, 2005).

\section{b. Transmisión intergeneracional}

La transmisión intergeneracional es un fenómeno que ocurre a nivel íntimo, en el núcleo familiar, y también a nivel más amplio, en la comunidad. Se entiende en relación con los patrones de uso y el traspaso de los códigos entre las generaciones integrantes de una comunidad. El concepto concebido para entender la noción de transmisión es "la direccionalidad de la transmisión", que se comprende como la interacción entre miembros de la comunidad que protagonizan el evento comunicativo. Los agentes involucrados en el evento pueden pertenecer a una misma generación o ser de otra distinta. En cualquier caso, la lengua que ocupa el niño para transmitir el mensaje a un adulto implicará la dirección niño-adulto, la respuesta será dirección adulto-niño. En situaciones de contacto, las lenguas utilizadas en las interacciones entre niños, jóvenes, adultos y ancianos alternan y dependerán de las condiciones de interacción en que se vean involucrados los agentes (Olate et al., 2013).

La motivación del uso y transmisión de una u otra lengua se relaciona con los condicionamientos sociohistóricos. La transmisión intergeneracional influye en los procesos de variación y cambio de lenguas (Thomason y Kaufman, 1988) y ocupa un lugar central en los procesos de transmisión cultural y vitalidad lingüística (Ghio y Fernández 2008; Landweer, 2000). 


\section{c. Géneros y discursos}

Los temas, géneros y discursos indican los tópicos que frecuentemente son hablados usando una u otra lengua en el seno de la comunidad. Por medio de ellos se puede observar la interacción lingüística en el contexto de los tópicos de conversación, lo que puede indicar las interacciones interpersonales dadas entre miembros de la comunidad.

\section{d. Actitudes y percepciones lingüisticas}

Finalmente, las percepciones y actitudes lingüísticas se entienden como unidades psicológicas complejas que involucran conocimientos, sentimientos y comportamientos, todos elementos sensibles a factores situacionales (Kristiansen, 1997; Olate y Henríquez, 2010; Olate y Bernales, 2014; Rojas, 2012). El papel que cumplen en las dinámicas interactivas y de uso de las lenguas es relevante, pues entrega información relacionada con valores sociales, prejuicios, construcción de estereotipos y posiciones de los hablantes en los grupos sociales (Silva Corvalán, 2001).

Las actitudes lingüísticas implican referencias explícitas a la lengua y se adquieren como factor de pertenencia de grupo, son determinadas por la cultura e influenciadas por la estructura social de la comunidad. La canalización de estas se produce a partir de enunciados valorativos o juicios sociolingüísticos, los que son entendidos como percepciones que tienen los hablantes sobre el lenguaje (Saville Troike, 2005). Las actitudes y creencias son importantes en los procesos de acomodación comunicativa de los hablantes. Estos se posicionan en su entorno social a partir de las dinámicas perceptivas que vivencian y que implican la apreciación de los discursos ajenos, la percepción del manejo de la cortesía, el discernimiento de la tendencia ideológica de los hablantes en el marco de sus propios modelos contextuales (Moreno Fernández, 2012, 2005).

La noción es útil para entender la interfaz lenguaje-sociedad, en el sentido de que las actitudes lingüísticas son comportamientos que ocurren en la esfera de lo público (Rojas, 2012; Garret, 2001), observándose tres ejes: (1) creencias; (2) emociones y (3) comportamientos; elementos que se perfilan como indicadores de la valoración/percepción que tienen los hablantes sobre una lengua o variedad lingüística y en los que se observan los aspectos sociales que afectan el uso de las lenguas o variedades (Rojas, 2012).

En una situación de bilingüismo, este componente es relevante, pues los hablantes evaluarán y valorarán las dos lenguas de la situación de bilingüismo, con lo que construirán juicios y expectativas sobre una y otra, generando apreciaciones utilitaristas, esencialistas o aquellas que naturalmente son influenciadas por factores sociales, laborales, históricos, entre otros. 


\section{e. Historia del territorio y las comunidades}

Los fenómenos de cambio, mantención y desplazamiento de las lenguas se deben analizar en el marco de los procesos de formación social e histórica de pueblos, Estados y comunidades. La historia plasma en sus procesos la dinámica sociolingüística de las lenguas (Antimil, 2016).

Estos procesos, en las situaciones de contacto, no son homogéneos, ni siguen, obligatoriamente, un único proceso de interacción, independiente de si la relación establecida sea simétrica o asimétrica. Hay procesos sociopolíticos -que involucran la incorporación de instituciones socioculturales ajenas a la lengua/sociedad dominadadesarrollados, los que afectan de manera divergente la mantención o desplazamiento de la lengua en los espacios territoriales, determinando tanto la forma del contacto como la dinámica de cambio/mantención. La historia nos permite la reconstrucción de coyunturas históricas que determinan la relación sociolingüística de las lenguas (Sepúlveda, 2004).

Por lo anterior, debemos destacar que en las líneas de la reconstrucción histórico-territorial y la interacción sociolingüística encontramos la génesis y el desarrollo de escenarios de contacto dados entre el mapuzugun y el castellano, los que se pueden definir desde la "Ocupación de La Araucanía" y canalizarse por medio de la colonización wingka, el tránsito fronterizo y la introducción de ámbitos de uso occidentalizantes. De aquí que relevar la historia de la comunidad sea un factor clave para darle legitimidad a una investigación que se concentre en la relación social y lingüística que establecen los hablantes y sus lenguas.

En esta línea, recordamos una idea previa, la historia del territorio contiene la historia de las lenguas, lugar donde se encuentran los contextos de interacción originarios que establecen las relaciones de poder y subordinación de códigos y hablantes. La reconstrucción de ámbitos de uso y otras dinámicas interactivas es una tarea clave para comprender el proceso histórico de bilingüismo y cambio lingüístico en la sociedad mapuche. La mirada se debe posicionar en los contextos, sus hablantes, las trayectorias y las memorias territoriales con el propósito de comprender las relaciones de complementariedad y antagonismo entre las lenguas y la configuración de la heterogeneidad sociolingüística del territorio.

\subsection{CON QUÉ INSTRUMENTOS PUEDE GENERARSE UN DIAGNÓSTICO}

Hasta el momento, en los trabajos de Olate et al. (2013), Olate (2014) y Antimil y Olate (en arbitraje) se ha utilizado un cuestionario lingüístico que explora el uso/relación entre el castellano y el mapuzugun en las categorías señaladas en la sección anterior. Otra herramienta útil para el desarrollo de una descripción es la entrevista semiestructurada que contemple temas relacionados con la introducción del castellano en la comunidad y en la vida de los participantes. 
Por otro lado, desde la historia, Millalen (2005) y Antimil (2012) presentan una metodología basada en fuente oral que no tiene formato de entrevista, sino que sigue patrones relacionados con el género ngütramkawün, que implica una situación dialógica en torno a un tema, donde ambos interactuantes construyen los escenarios. Esta última metodología permite explorar la historia de la comunidad, su formación, organización económica, procesos de escolarización y su estructura sociopolítica.

\subsection{LA COMPARACIÓN ENTRE COMUNIDADES}

Un aspecto fundamental de esta línea de investigación se explicita en Olate et al. (2013, p. 281) que sostienen que "Se hace necesario, en este contexto, la realización de estudios comparativos entre diversas comunidades bilingües mapuche/castellano, ya que la variabilidad intercomunitaria es un fenómeno que puede relativizar los usos de ambos códigos al interior de las comunidades".

Los trabajos de Henríquez $(2014,2015)$ van en esta línea comparativa, pero se ocupan, principalmente, de las actitudes en niños y de la interacción en la comunidad. No se presenta un énfasis que permita generar el escenario de fondo (complejo) de la historia del mapuzugun y el castellano en las comunidades. A pesar de ello, los estudios de Henríquez comparan el "estado de la lengua" y destacan los procesos de desplazamiento en las comunidades.

La actual perspectiva busca complementar dos disciplinas: la sociolingüística y la historia; pues a partir de ambas se puede articular una mirada complementaria $-\mathrm{y}$ comprensiva- de la relación sociolingüística e histórica de las lenguas hasta nuestros días.

\section{CONCLUSIÓN}

En este artículo se ha propuesto la profundización de la posición que hemos llamado sociolingüística interactiva e histórica por medio de la discusión de conceptos y metodologías. Además se ha relevado la importancia de las dinámicas sociolingüísticas de las comunidades y el marco histórico que las regula.

La discusión la hemos establecido a partir de la crítica de la noción de "estado sociolingüístico de la lengua" que es promovida por enfoques que generalizan los estados de la lengua, obedeciendo a puntos de vista unidireccionales y hegemónicos que hacen prevalecer el estado de un código sobre otro, dejando de lado las relaciones lingüístico-culturales y la respectiva adecuación de los hablantes y las comunidades a los escenarios interactivos, entendidos como situaciones históricas, dinámicas y complejas en cambio constante.

También se abordó la emergencia del bilingüismo y el contacto que se da en estas situaciones (Olate, 2017), destacando el contacto histórico y la construcción del hablante bilingüe mapuche/castellano. Con esta idea se busca contextualizar la situación de relación mapuzugun/castellano a un escenario de bilingüismo social forjado durante el proceso histórico de la relación -social y lingüística- entre el 
castellano y la lengua mapuche. Esta dimensión del bilingüismo y el contacto permite consignar la emergencia de variedades de contacto y observar las condiciones históricas de interacción que han transitado los hablantes.

Respecto del problema de mantención y desplazamiento del mapuzugun, mediante la sociolingüística interactiva e histórica se pueden establecer escenarios realistas que permitan dimensionar los procesos de cambios graduales, cíclicos o dialécticos que ocurren en las lenguas a partir de presiones extralingüísticas. Por otra parte, es necesario considerar el posicionamiento político-lingüístico y la acción político-lingüística que generan los agentes difusores de la lengua y su revitalización. Finalmente, los hechos históricos y las trayectorias sociolingüísticas (Wittig, 2011) hay que observarlos en cuanto procesos de interacción y adaptación en que los hablantes actúan presionados por factores extralingüísticos (historia, política, actitudes, ideologías). Para finalizar presentamos dos reflexiones que sirven de base para proyecciones posteriores:

1. El desarrollo histórico de las comunidades contiene la interacción lingüística de sus integrantes, por lo que el ejercicio de la reconstrucción histórico-territorial es relevante para comprender la situación actual de los hablantes y sus lenguas. Esta última no nos permite hablar de estados sociolingüísticos, sino más bien de procesos sociolingüísticos en curso, cuyos resultados dependen de factores extralingüísticos, principalmente, vinculados con iniciativas que promuevan un posicionamiento político-lingüístico basado en la acción.

2. Las descripciones sociolingüísticas más actuales no han considerado las condiciones de interacción particulares generadas en las comunidades mapuches. El estudio de la interacción entre una lengua ' $x$ ' $y$ una lengua ' $y$ ' permite caracterizar las dinámicas sociolingüísticas de uso y transmisión de los códigos y registros que circulan al interior de las comunidades, promoviendo una visión dinámica de los procesos de formación de variedades y de desplazamiento y mantención de las lenguas en el espacio geosociocultural. Por lo anterior, es importante discutir los conceptos y las herramientas teóricas que permiten abordar el fenómeno de la interactividad, entendiendo que en situaciones de contacto el estado de una lengua no es estático, sino dinámico y continuo, lo que produce la generación de una multiplicidad de procesos que pueden derivar en: la emergencia de variedades de lengua, el desplazamiento y cambio de código, la mantención y reestructuración de sistemas, la vernacularización y etnificación de variedades, estados bilingües diversos, identidad y reconocimiento de la lengua, entre otros. Las comunidades están condicionadas a factores históricos, geográficos y socioculturales, que repercuten en las dinámicas lingüísticas y sociolingüísticas comunitarias. Las lenguas no pueden examinarse desde marcos estáticos, más bien se deben observar como entidades activas, dinámicas y de tránsito continuo en la historia sociolingüística de los hablantes. 
Más allá del estado de vida de las lenguas...

\begin{abstract}
Universidad de La Frontera*
Facultad de Educación, Ciencias Sociales y Humanidades

Escuela de Pedagogía

Departamento de Lenguas, Literatura y Comunicación

Núcleo de Investigación en Ciencias Sociales

Avda. Francisco Salazar 01145, casilla 24 D. Temuco (Chile)

aldo.olate@ufrontera.cl
\end{abstract}

El presente trabajo se realiza gracias al apoyo de los proyectos DIUFRO DI-13003 "Comunidades de habla e interacción lingüística. Un acercamiento a las dinámicas sociolingüísticas entre el mapuzugun y el castellano; y FONDECYT 11130712 "Contacto lingüístico y gramatical: el castellano hablado en comunidades mapuches. Un acercamiento desde el contacto y la tipología". La información del proyecto se puede encontrar en www.contactomapucheyespañol.cl

\title{
OBRAS CITADAS
}

Antimil, Jaime. (2016) "Colonialismo y procesos sociolingüísticos en territorios del Ngulumapu". En Canales, Pedro y Marian Moreno (Eds.). Los claroscuros del debate (pueblos indígenas, colonialismo y subalternidad en América del Sur, siglos XX-XXI). Santiago: Ariadna Ediciones, 195-218.

- (2012). Panko ka Tranantue Mapu ñi Kuifike Zungu. Historia de las comunidades de Panko y Tranantúe desde la segunda mitad del siglo XIX hasta 1950. Tesis para optar al grado de Licenciado en Educación. Temuco: Universidad de La Frontera.

Antimil, Jaime y Olate, Aldo. "Procesos sociolingüísticos, historia y colonialismo chileno en una comunidad rural mapuche". En arbitraje, Revista Universum.

Bengoa, José. (2014). Mapuche, colonos y Estado Nacional, Santiago: Catalonia.

— (2007). Historia de los antiguos mapuches del sur, Santiago: Catalonia. (2000). Historia del pueblo mapuche. Siglos XIX Y XX, Santiago: LOM.

Comunidad de Historia Mapuche. (2015). Awükan ka kuxankan zugu wajmapu mew. Violencias coloniales en Wajmapu. Temuco: Ediciones Comunidad de Historia Mapuche.

Croese, Robert. (1983). "Algunos resultados de un trabajo de campo sobre las actitudes de los mapuches frente a su lengua materna". Revista de Lingüistica Teórica y Aplicada, 21, 23-34.

Durán, Teresa y Ramos, Nelly. (1989). "Interacción mapudungun-castellano vinculada a contextos educacionales en una población mapuche rural". Lenguas Modernas 16, 97-113.

(1988). Castellanización formal en la Araucanía a través de la escuela". Lenguas Modernas 15, 131-154. 
_ (1987). "Incorporación del español por los mapuches del centro sur de Chile durante el siglo XIX". Lenguas Modernas 14, 179-196.

_ (1986). "Incorporación del español por los mapuches del centro sur de Chile durante los siglos XVI, XVII y XVIII". Lenguas Modernas 13, 17-36.

Fishman, Joshua. (1982). Sociología del lenguaje. Madrid: Cátedra.

(1974). "Conservación y desplazamiento del idioma como campo de investigación". En Garvin, Paul y Yolanda Lastra (Eds.). Antología de estudios de etnolingüística y sociolingüística. México: UNAM.

Garret, Peter. (2001). "Language Attitudes and Sociolinguistics". Journal of Sociolinguistics 5(4), 626-631.

Ghio, Elsa y María Delia, Fernández. (2008). Lingüistica sistémico funcional. Aplicaciones a la lengua española. Santa Fe: Universidad Nacional del Litoral, Wadhuter Editores.

Gianelli, Luciano. (2007). "Dominios y redes de empleo del mapuzugun en el marco rural mapuche". Signos lingüisticos 5, 97-118

Godenzzi, Juan Carlos. (2007). "El español de América y el español de los Andes: universalización, vernacularización y emergencia". En Schrader-kniffki, Martina y Laura Morgenthaler (Eds.). La Romania en interacción: entre contacto, historia y política. Ensayos en homenaje a Klaus Zimmermann. Frankfurt: Vervuet- Iberoamericana.

— (2003). "El castellano en poblaciones indígenas: contextos sociolingüísticos y criterios para la enseñanza". En Jung, I. y J. E. López (Eds), Abriendo la escuela. Lingüistica aplicada a la enseñanza de lenguas. Madrid: Morata.

Gundermann, Hans. (2005). "Estudios del contexto sociolingüístico de comunidades aymaras, atacameñas y mapuche de Chile". En J. Vergara y H. Gundremann (ed): Descripción del contexto sociolingüístico en comunidadesindígenas de Chile. Santiago: Programa EIB-MINEDUC- programa Orígenes, 13-97.

Gundermann, Hans, Caniguan, Jaqueline, Clavería, Alejandro y Faúndez, César. (2011). "El mapudungun, una lengua en retroceso". Atenea, 503, 111-131.

_ (2009). "Permanencia y desplazamiento, hipótesis acerca de la vitalidad del mapuzugun". Revista de Lingüística Teórica y Aplicada 47, 37-60.

—_ (2008). Perfil Sociolingüistico de comunidades mapuches de la región del Biobio, Araucanía, los Ríos y los Lagos. Informe de investigación: CONADI-UTEM.

Henríquez, Marisol. (2015). "Ámbitos de uso del mapudungun en comunidades Pewenches y Lafkenches de la región del Biobío". Lingüística y Literatura, 185-204.

_ (2014). "Estado del mapudungun en comunidades pewenches y lafkenches de la región del Bío-Bío: el caso de los escolares". Revista de Lingüística Teórica y Aplicada 52(2), 13-40. 
Kristiansen, Tore. (1997) "Languages Attitudes in a Danish Cinema". En Coupland, Nikolas y Jaworski, Adam (Eds), Sociolinguistics. A reader and coursebook. Nueva York: ST. Martin's Press.

Lagos, Cristián. (2013). "Revitalización lingüística del mapudungún en entornos urbanos y no urbanos en Chile: el impacto del programa de educación intercultural bilingüe (PEIB)"'. Lenguas Modernas 41, 67-83.

— (2012). "El Mapudungun en Santiago de Chile: vitalidad y representaciones sociales en los mapuches urbanos". Revista de Lingüística Teórica y Aplicada 50 (1), 161-184.

Lagos, Cristián y Espinoza, Marco. (2013). "La planificación lingüística de la lengua mapuche en Chile a través de la historia". Lenguas Modernas 42, 47-62.

Landweer, Lynn. (2000) "Endangered languages. Indicators of ethnolinguistic vitality". Notes on Sociolinguistics 5.1.

McColl Millar, Robert. (2012). "Social History and the Sociology of Language". En Hernández-Campoy, Juan y Conde-Silvestre, Camilo (Eds): The Handbook of Historical Sociolinguistics. Oxford: Wiley Blackwell.

Millalén, José. (2005). Lof Mapu Mañiuko comuna de Galvarino, Región de La Araucanía: Un intento por escribir su historia a través de relatos orales. Tesis para optar al grado de Licenciado en Educación. Temuco: Universidad de La Frontera.

Moreno Fernández, Francisco. (2012). Sociolingüistica cognitiva. Proposiciones, escolios y debates. Madrid: Vervuert-Iberoamericana.

— (2005). Principios de sociolingüistica y sociología del lenguaje. Barcelona: Ariel.

Nahuelpán, Héctor. (2013). "Las 'zonas grises' de las historias mapuche. Colonialismo internalizado, marginalidad y políticas de la memoria”. Revista de Historia Social y de las Mentalidades 17, 9-31.

_ (2012). "Formación colonial del estado y desposesión en Ngulumapu". En Tain fijke xipa rakizuameluwun. Historia, colonialismo y resistencia desde el país Mapuche. Editado por Comunidad de Historia Mapuche. Temuco: Ediciones Comunidad de Historia Mapuche, 123-156.

Olate, Aldo. (2017). "Contacto lingüístico mapuzugun/castellano. Aspectos históricos, sociales y lingüísticos. Revisión bibliográfica y propuesta de análisis desde la dimensión morfosintáctica y tipológica”. Por aparecer revista Onomázein, 36.

— (2014). "Transmisión generacional del mapudungun en una comunidad bilingüe". En Azócar, Alonso; Luis Nitrihual y Aldo Olate (eds.): Lenguas, Literatura y Comunicación 20 años de investigación en la Universidad de La Frontera. Temuco: Colección Espiral Social.

Olate, Aldo y Bernales, Mario. (2014). "Variedades del castellano en interacción: Ámbitos de uso y actitudes en una comunidad rural". Boletín de Filología, 49(2), 187-213. 
Olate, Aldo; Alonqueo, Paula; y Caniguan, Jaqueline. (2013). "Interactividad lingüística castellano/mapudungun de una comunidad rural bilingüe". Alpha, 37, 265-284.

Olate, Aldo y Henríquez, Marisol. (2010). "Actitudes lingüísticas de profesores mapuche de educación básica: vigencia y enseñanza del mapudungun en el contexto educativo". Lingüistica y Literatura 22, 103-116.

Pinto, Jorge. (2000). La formación del estado y la nación mapuche y el pueblo mapuche. De la inclusión a la exclusión. Santiago: Colección IDEA.

Rojas, Darío. (2012). "Actitudes lingüísticas de hispanohablantes de Santiago de Chile: creencias sobre la corrección idiomática”. Onomázein 26, 69-93.

Romaine, Suzanne. (1996). El lenguaje en la sociedad. Una introducción a la sociolingüistica. Barcelona: Ariel.

Salas, Adalberto. (2006). El mapuche o araucano, Santiago: Centro de Estudios Públicos. (1983). ¿Alfabetizar y enseñar en mapudungu? ¿alfabetizar y enseñar en castellano? Alternativas para la escuela rural en La Araucanía chilena. Revista de Lingüistica Teórica y Aplicada 21, 59-64.

Saville Troike, Muriel. (2005). Etnografia de la Comunicación.Buenos Aires: Prometeo Libros.

Sepúlveda, Isidro. (2004). "Tendencias historiográficas en el siglo XX”. En Casado, Blas (Ed.): Tendencias historiográficas actuales. Madrid: UNED.

Silva-Corvalán, Carmen. (2001). Sociolingüistica y Pragmática del español. Georgetown University Press. Washinton, D.C.

Teiller, Fernando. (2013). "Vitalidad lingüística del mapudungun en Chile y epistemología del hablante". Revista de Lingüistica Teórica y Aplicada 51(1), 53-70.

Thomason, Sara y Terrence Kaufman. (1988). Language contact, creolization, and genetic linguistics. Los Ángeles: University of California Press.

Wittig, Fernando. (2009). "Desplazamiento y vigencia del mapudungun en Chile: Un análisis desde el discurso reflexivo de los hablantes urbanos". Revista de Lingüística Teórica y Aplicada, 47, 135-155.

— (2011). "Adquisición y transmisión del mapudungún en hablantes urbanos". Literatura y lingüistica, 23, 193-211.

Zavala, José. (2008). Los mapuches del siglo XVIII, Temuco: Ediciones Universidad Católica de Temuco.

Zúñiga, Fernando. (2007). "Mapudunguwelaymi am? ¿Acaso ya no hablas mapudungún? Acerca del estado actual de la lengua mapuche". Estudios Públicos 105, 9-24. 